\title{
Relative disagreement among different software packages in PET-flow quantitation: An appeal for consistency
}

\author{
Thomas H. Schindler, MD, PhD, ${ }^{\mathrm{a}}$ and Ines Valenta, $\mathrm{MD}^{\mathrm{a}}$ \\ a Division of Nuclear Medicine, Mallinckrodt Institute of Radiology, Washington University \\ School of Medicine, St. Louis, MO
}

Received Jan 24, 2019; accepted Jan 24, 2019

doi: $10.1007 / \mathrm{s} 12350-019-01633-y$

\section{See related article, pp. 1225-1233}

Positron emission tomography (PET) is increasingly applied to assess myocardial perfusion in conjunction with global and regional myocardial blood flow (MBF) quantitation in $\mathrm{mL} \cdot \mathrm{g} \cdot \mathrm{min}$ in patients with suspected and/ or known CAD. ${ }^{1,2}$ While the stress-related regional myocardial perfusion defects commonly identify the "culprit", or the most-advanced CAD lesion in multivessel disease, the hemodynamic significance of lesssevere, intermediate CAD lesions with still homogenous radiotracer uptake may be identified by corresponding regional reductions in hyperemic $\mathrm{MBF}$ and/or myocardial flow reserve $(\mathrm{MFR}=\mathrm{MBF}$-stress $/ \mathrm{MBF}-$ rest $){ }^{2,3} \mathrm{In}$ this respect, the concurrent assessment of PET-determined MFR has been appreciated to provide not only the additional diagnostic value, but it carries also important prognostic information in patients with subclinical and clinically manifest CAD. ${ }^{4,5}$ The reproducibility of such MBF quantitation with PET has been performed mainly in healthy volunteers with and without cardiovascular risk factors. ${ }^{6}$ These data have convincingly demonstrated that PET-determined serial MBFs during pharmacologic-stimulated hyperemia and at rest can be employed reliably and are reproducible for quantitation of effects of preventive medical intervention, gastricbypass-induced weight loss, and/or behavioral

Reprint requests: Thomas H. Schindler MD, PhD, Division of Nuclear Medicine, Mallinckrodt Institute of Radiology, Washington University School of Medicine, 510 S. Kingshighway, St. Louis, MO, 63110; thschindler@wustl.edu

J Nucl Cardiol 2020;27:1234-6.

1071-3581/\$34.00

Copyright (C) 2019 American Society of Nuclear Cardiology. interventions related to weight, diet, and physical activity on coronary circulatory dysfunction. ${ }^{1,7}$ Subsequently, the reproducibility of PET-flow studies among different software tools was investigated. ${ }^{8-11}$ For example, Slomka et al. ${ }^{8}$ compared MBF values obtained from three software tools such as QPET, syngo MBF, and PMOD in individuals with or without obstructive CAD. And indeed, the global and regional MBF and MFR values did closely correlate between the three software packages (correlation coefficient $r^{2}$ for global values ranging from 0.88 to 0.92 and for regional values from 0.78 to 0.94 , respectively), which was reflected by similar mean MFR values (QPET: $3.39 \pm 1.22$, Syngo MBF: $3.41 \pm 0.76$, and PMOD: $3.66 \pm 1.19$, respectively).

In this issue of the Journal of Nuclear Cardiology, Monroy-Gonzalez et al. ${ }^{12}$ report that in patients with normal stress-rest PET perfusion images, two out of three comparisons were outside the limits of agreement, while in patients with reversible perfusion deficits suggesting ischemia, comparisons of all software packages of global hyperemic MBFs and MFR were outside the limits of established agreement. In addition, there was an agreement of hyperemic MBFs and MFR mostly only for the LAD distribution. Such observations outline that results of MBF quantitation with different software packages are not necessarily interchangeable. Such observations may contradict the results from Slomka et al.'s study ${ }^{8}$ which described quite similar MFR values for each vascular territory except for some disagreement in respect of the RCA distribution due to the influence of high spill-over fraction, a problem familiarly known for ${ }^{13} \mathrm{~N}$-ammonia PET images. PETflow studies with other positron-emitting radiotracers such as ${ }^{82}$ Rubidium and ${ }^{15} \mathrm{O}$-water also yielded a goodto-excellent agreement between the observations made using different software packages. ${ }^{11,13,14}$ The reason for these discordant observations may remain uncertain and 
may be related to methodological differences or reorientation, contour detection, left ventricular segmentation, and the sampling of the left ventricle blood pool time activity curve as per the authors' statement. ${ }^{12}$ Overall, the contrasting observations in MBF quantitation with different software packages may be surprising at first sight, but they may be reconciled when looking more into the details. For example, there is a distinct variability of individual hyperemic MBF as expressed by the coefficient of variation (COV) ranging 0.49 to 1.34 for hyperemic MBF. ${ }^{6}$ In this direction, the calculation of the MFR, which reflects the ratio of hyperemic MBF to MBF at rest, affords a potential advantage of less variability than that for the hyperemic MBFs measured. ${ }^{15}$ If a percentage methodological error is made (e.g., positioning of the region of interest for the arterial input function) during hyperemic flows and a similar error is made during rest MBF quantitation, then the errors will cancel out. Thus, when calculating the MFR, any methodological differences among software packages may widely cancel out given the same percentage error is made both during hyperemic vasodilator stress and at rest. For example, in a multicenter trial with a head-to-head comparison of MBF quantitation between gadolinium $\mathrm{CMR}$ and ${ }^{13} \mathrm{~N}$-ammonia PET imaging, the MFR between the two modalities correlated well $(r=0.75)$ but not so for hyperemic and rest MBFs $\left(r=0.37\right.$ and $r=0.32$, respectively). ${ }^{16}$ The results of the current ${ }^{12}$ and other studies ${ }^{13,17,18}$ emphasize the relative but significant differences in values of hyperemic MBFs and MFR related to methodological differences of software packages in the quantitation of MBFs and also to a certain observer dependency (e.g., semi-manual segmentation of the left ventricle and positioning of the ROI for the arterial input function). The variability of quantified hyperemic flows can also be appreciated by the range in the standard deviation (SD) of the mean values. This has important clinical implications as the optimal threshold for hyperemic MBFs and MFR to define between normal and abnormal flows may be derived from mean flows values and its SD in healthy volunteers. Abnormal hyperemic MBF and MFR may be present when these flow parameters are \pm 2 standard deviations (SDs) below the limits of normal values on the basis of hyperemic MBFs in a healthy study population without cardiovascular risk factors. ${ }^{1}$ For example, stress-rest ${ }^{13} \mathrm{~N}$-ammonia PET/CT study in healthy volunteers resulted in a mean hyperemic MBF of $2.37 \pm 0.49 \mathrm{~mL} \cdot \mathrm{min} \cdot \mathrm{g}$ and MFR of $3.38 \pm 0.67$. Consequently, the thresholds to signify reduced hyperemic flow increases (2 SD below the mean) would be $1.39 \mathrm{~mL} \cdot \mathrm{g} \cdot \mathrm{min}$ for hyperemic $\mathrm{MBF}$ and 2.04 for the MFR, respectively. ${ }^{19}$
Taken together, Monroy-Gonzalez et al. ${ }^{12}$ have to be complemented as their results outline an important issue of a relative but likely clinically important disagreement among software packages in flow quantitations. The observed range of relative discordance $^{12,13,17}$ may affect the diagnostic accuracies of hyperemic MBFs and MFR in the identification and characterization of hemodynamic significant downstream effects of epicardial lesions. ${ }^{20}$ For this reason, each PET facility should strive for consistency not only in the choice of positron-emitting radiotracer and remaining manual steps in the processing of the MBF quantitation but also in their software package for optimal patient care.

\section{Disclosure}

Thomas H. Schindler was financially supported by Advanced Accelerator Applications, Geneva, Switzerland. Ines Valenta has nothing to disclose.

\section{References}

1. Schindler TH, Schelbert HR, Quercioli A, Dilsizian V. Cardiac PET imaging for the detection and monitoring of coronary artery disease and microvascular health. JACC Cardiovasc Imaging 2010;3:623-40.

2. Schindler TH. Myocardial blood flow: Putting it into clinical perspective. J Nucl Cardiol 2016;23:105671.

3. Gould KL, Johnson NP, Bateman TM, Beanlands RS, Bengel FM, Bober R, et al. Anatomic versus physiologic assessment of coronary artery disease. Role of coronary flow reserve, fractional flow reserve, and positron emission tomography imaging in revascularization decision-making. J Am Coll Cardiol 2013;62:1639-53.

4. Murthy VL, Bateman TM, Beanlands RS, Berman DS, BorgesNeto $\mathrm{S}$, Chareonthaitawee $\mathrm{P}$, et al. Clinical quantification of myocardial blood flow using PET: Joint position paper of the SNMMI cardiovascular council and the ASNC. J Nucl Cardiol 2018;25:269-97.

5. Lu DY, Yalcin H, Yalcin F, Zhao M, Sivalokanathan S, Valenta I, et al. Stress myocardial blood flow heterogeneity is a positron emission tomography biomarker of ventricular arrhythmias in patients with hypertrophic cardiomyopathy. Am J Cardiol 2018;121:1081-9.

6. Schindler TH, Zhang XL, Prior JO, Cadenas J, Dahlbom M, Sayre $\mathrm{J}$, et al. Assessment of intra- and interobserver reproducibility of rest and cold pressor test-stimulated myocardial blood flow with (13)N-ammonia and PET. Eur J Nucl Med Mol Imaging 2007;34:1178-88.

7. Quercioli A, Montecucco F, Pataky Z, Thomas A, Ambrosio G, Staub C, et al. Improvement in coronary circulatory function in morbidly obese individuals after gastric bypass-induced weight loss: Relation to alterations in endocannabinoids and adipocytokines. Eur Heart J 2013;34:2063-73.

8. Slomka PJ, Alexanderson E, Jacome R, Jimenez M, Romero E, Meave A, et al. Comparison of clinical tools for measurements of regional stress and rest myocardial blood flow assessed with ${ }^{13} \mathrm{~N}$ ammonia PET/CT. J Nucl Med 2012;53:171-81. 
9. Dunet V, Klein R, Allenbach G, Renaud J, deKemp RA, Prior JO. Myocardial blood flow quantification by Rb-82 cardiac PET/CT: A detailed reproducibility study between two semi-automatic analysis programs. J Nucl Cardiol 2016;23:499-510.

10. Dekemp RA, Declerck J, Klein R, Pan XB, Nakazato R, Tonge C, et al. Multisoftware reproducibility study of stress and rest myocardial blood flow assessed with 3D dynamic PET/CT and a 1tissue-compartment model of ${ }^{82} \mathrm{Rb}$ kinetics. J Nucl Med 2013;54:571-7.

11. Nesterov SV, Deshayes E, Sciagra R, Settimo L, Declerck JM, Pan $\mathrm{XB}$, et al. Quantification of myocardial blood flow in absolute terms using (82)Rb PET imaging: The RUBY-10 Study. JACC Cardiovasc Imaging 2014;7:1119-27.

12. Monroy-Gonzalez A, Juarez-Orozco LE, Han C, Vedder I, Vallez Garcia D, Borra R, et al. Software reproducibility of myocardial blood flow and flow reserve quantification in ischemic heart disease: A $13 \mathrm{~N}$-ammonia PET study. J Nucl Cardiol 2019: in press.

13. Sunderland JJ, Pan XB, Declerck J, Menda Y. Dependency of cardiac rubidium- 82 imaging quantitative measures on age, gender, vascular territory, and software in a cardiovascular normal population. J Nucl Cardiol 2015;22:72-84.

14. Harms HJ, Nesterov SV, Han C, Danad I, Leonora R, Raijmakers $\mathrm{PG}$, et al. Comparison of clinical non-commercial tools for automated quantification of myocardial blood flow using oxygen-15labelled water PET/CT. Eur Heart J Cardiovasc Imaging 2014;15:431-41.
15. Schindler TH, Dilsizian V. PET-determined hyperemic myocardial blood flow: Further progress to clinical application. J Am Coll Cardiol 2014;64:1476-8.

16. Morton G, Chiribiri A, Ishida M, Hussain ST, Schuster A, Indermuehle A, et al. Quantification of absolute myocardial perfusion in patients with coronary artery disease: Comparison between cardiovascular magnetic resonance and positron emission tomography. J Am Coll Cardiol 2012;60:1546-55.

17. Oliveira JB, Sen YM, Wechalekar K. Intersoftware variability impacts classification of cardiac PET exams. J Nucl Cardiol. 2018. https://doi.org/10.1007/s12350-018-1444-z.

18. Yalcin H, Valenta I, Zhao M, Tahari A, Lu DY, Higuchi T, et al. Comparison of two software systems for quantification of myocardial blood flow in patients with hypertrophic cardiomyopathy. J Nucl Cardiol. 2018. https://doi.org/10.1007/s12350-0171155-x.

19. Quercioli A, Pataky Z, Vincenti G, Makoundou V, Di Marzo V, Montecucco F, et al. Elevated endocannabinoid plasma levels are associated with coronary circulatory dysfunction in obesity. Eur Heart J 2011;32:1369-78.

20. Valenta I, Quercioli A, Schindler TH. Diagnostic value of PETmeasured longitudinal flow gradient for the identification of coronary artery disease. JACC Cardiovasc Imaging 2014;7:38796.

Publisher's Note Springer Nature remains neutral with regard to jurisdictional claims in published maps and institutional affiliations. 